PNNL-13281

\title{
Comparison of Nozzles and Flow Straighteners for Tank Waste Sluicing Applications
}

\author{
O. D. Mullen \\ D. R. Jackson
}

September 2000

Prepared for

The U.S. D epartment of Energy

Under Contract DE-AC06-76RLO 1830

This work is funded by the Office of Science and Technology within the U.S. D epartment of Energy's O ffice of Environmental Management under the Tanks Focus Area Program 
DISCLAIMER

This report was prepared as an account of work sponsored by an agency of the Unit Government. Neither the United States Government nor any agency thereof, nor Battelle $]$ Institute, nor any of their employees, makes any warranty, express or implied, or assumes liability or responsibility for the accuracy, completeness, or usefulness of any inf apparatus, product, or process disclosed, or represents that its use would not infringe owned rights. Reference herein to any specific commercial product, process, or service name, trademark, manufacturer, or otherwise does not necessarily constitute or $\mathrm{i}$ endorsement, recommendation, or favoring by the United States Government or an: thereof, or Battelle Memorial Institute. The views and opinions of authors expressed here necessarily state or reflect those of the United States Government or any agency thereof.

\title{
PACIFIC NORTHWEST NATIONAL LABORATORY
}

\author{
operated by \\ BATTELLE \\ for the \\ UNITED STATES DEPARTMENT OF ENERGY \\ under Contract DE-ACO6-76RLO1830
}

Printed in the United States of America

A vailable to DOE and DOE contractors from the

Office of Scientific and Technical Information,

P.O. Box 62, Oak Ridge, TN 37831-0062;

ph: (865) 576-8401

fax: (865) 576-5728

ernail: reports@adonis.osti.gov

Available to the public from the National Technical Information Service,

U.S. Department of Commerce, 5285 Port Royal Rd., Springfield, V A 22161

ph: (800) 553-6847

fax: (703) 605-6900

email: orders@ntis.fedworld.gov

online ordering: http:llwww.ntis.gov/ordering.htm

@ This document was printed on recycled paper. 
PNNL-13281

\title{
Comparison of Nozzles and Flow Straighteners for Tank Waste Sluicing Applications
}

\author{
O. D. Mullen \\ D. R. Jackson
}

September 2000

Prepared for

The U.S. D epartment of Energy

Under Contract DE-AC06-76RLO 1830

This work is funded by the $\mathrm{O}$ ffice of Science and Technology within the U.S. D epartment of Energy's O ffice of Environmental Management under the Tanks Focus Area Program 
PNNL-13281 


\section{Summary}

The purpose of these tests was to provide quantitative and qualitative comparisons for several different sluice nozzle/flow straightener combinations to support past qualitative reviews and observations and to provide information that may be useful for future deployment of in-tank sluicing systems on the Hanford site. The specific tests were designed to assess the relative coherence of water streams produced by each different nozzle and flow straightener combination. The assessments presumed applicability for sluicing waste from underground storage tanks. The criteria for comparison were impact force produced by the stream impinging on a target plate at various distances from the nozzle and coherence of the streams demonstrated by the variation of force on two different size targets.

As a result of these tests, it was determined that the standard Hanford flow straightener is measurably less effective than a commercial fire fighting flow straightener at producing a coherent stream when used with the standard Hanford nozzle and that a lighter and more compact fire fighting deluge nozzle will deliver a stream of equal coherence to that from the Hanford nozzle when either nozzle is used with the commercial flow straightener.

In conclusion, the data contained in this report supports a recommendation to update the Hanford sluicing nozzle and flow straightener components to utilize commercially developed and proven designs. 


\section{Contents}

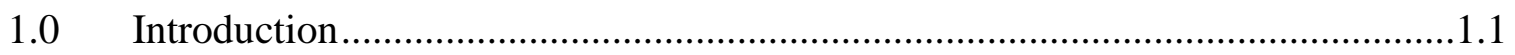

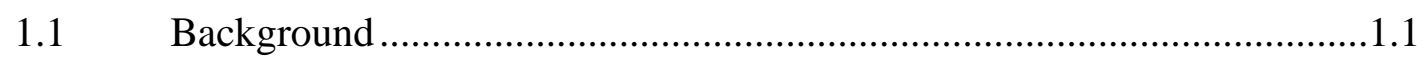

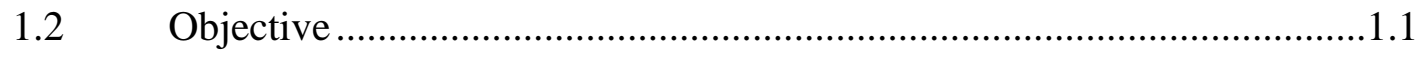

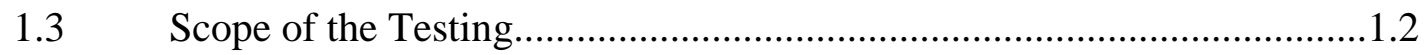

$2.0 \quad$ Procedure

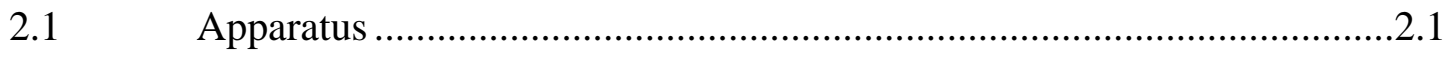

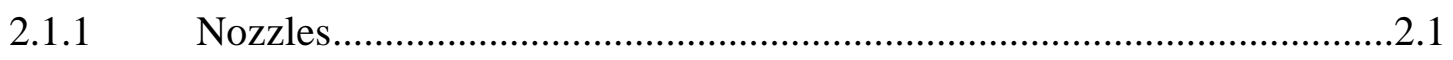

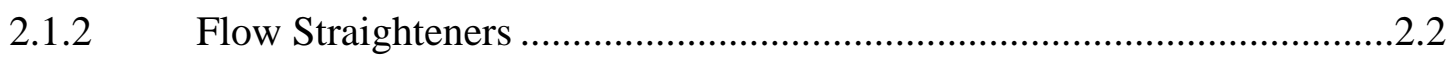

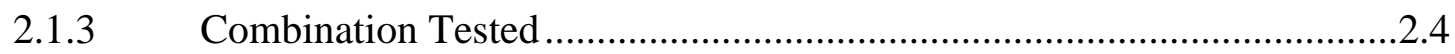

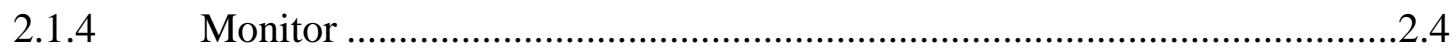

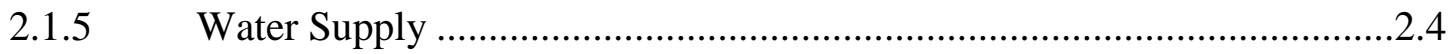

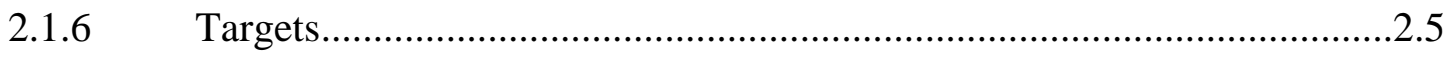

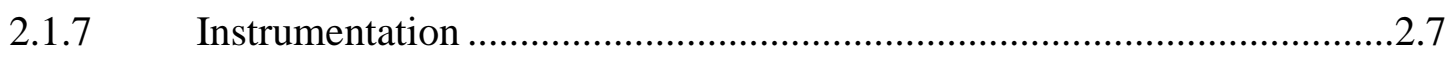

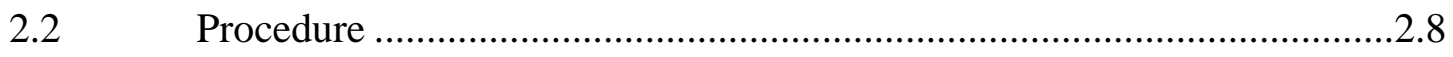

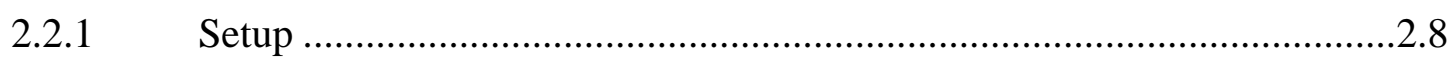

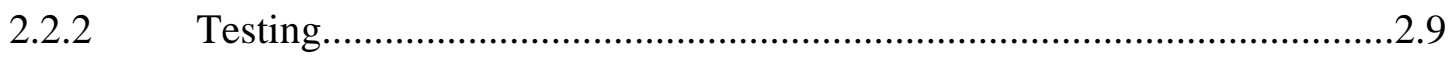

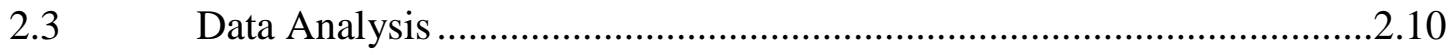

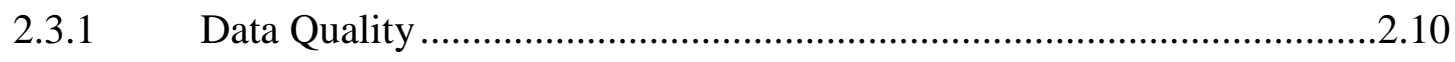

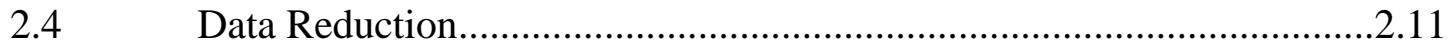

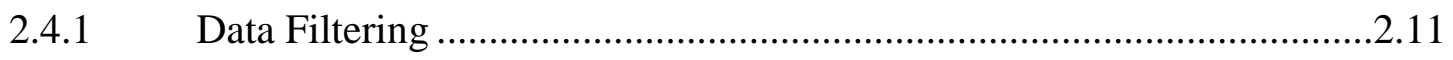

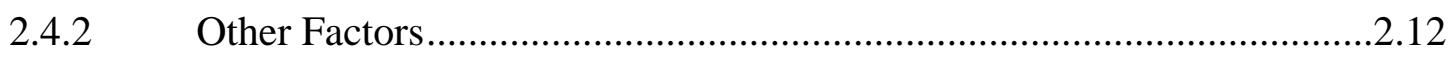

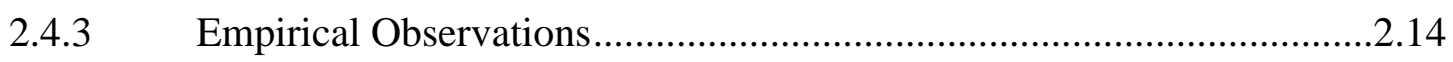

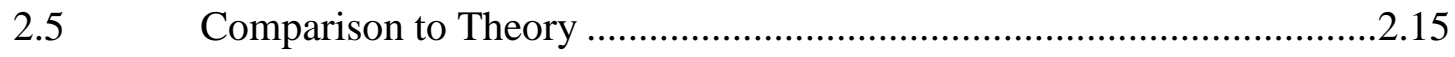

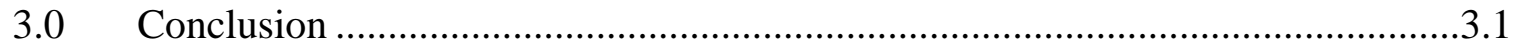

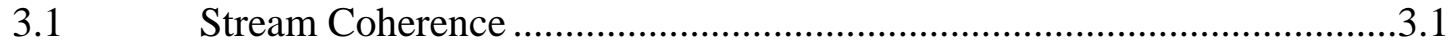

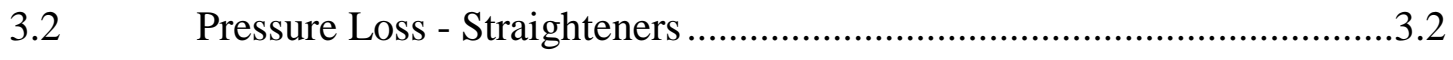

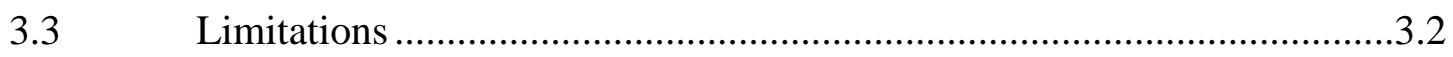

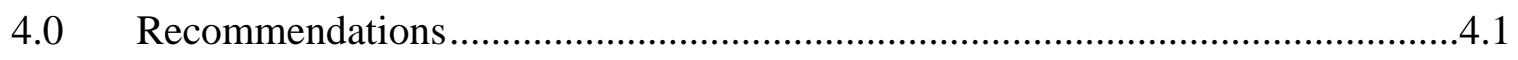

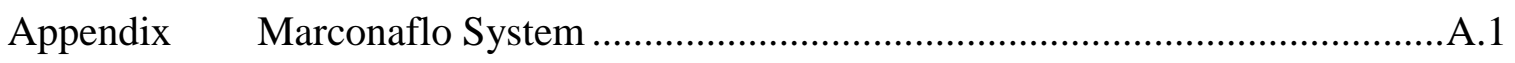




\section{Figures}

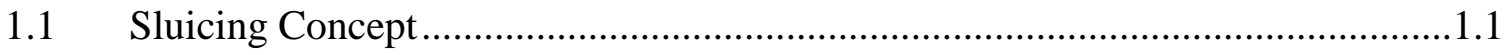

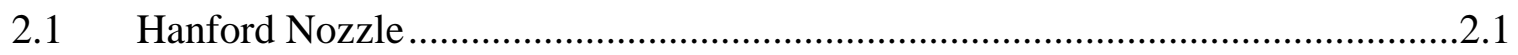

2.2 Elkhart \#181 Brass Deluge Tip ....................................................................2.2

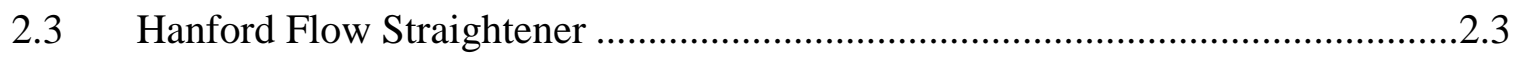

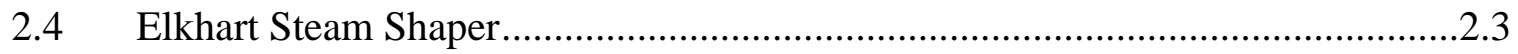

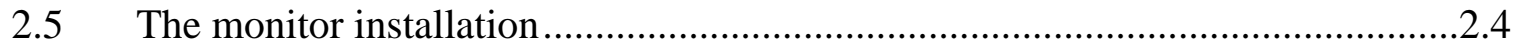

2.6 Rear view of target with 54-cm (21-inch) plate attached ...................................

2.7 Front oblique view of target with $27-\mathrm{cm}(10.5 \mathrm{inch})$ plate only ...........................

2.8 Data plot for Test H25 showing non-linear drift in Fz .................................2.11

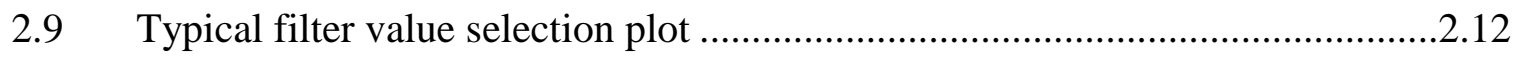

2.10 Plot of wind speed and direction during the testing.......................................13

2.11 Test H17 - Elkhart Nozzle with Elkhart Steam Shaper, 19.2 m (63 ft) .............2.14

2.12 Test H18 - Hanford Standard Nozzle with Elkhart Steam Shaper,

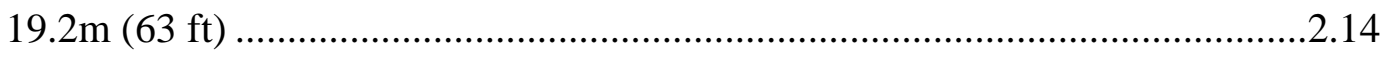

2.13 Test H19A - Hanford Nozzle with Hanford Flow Straightener,

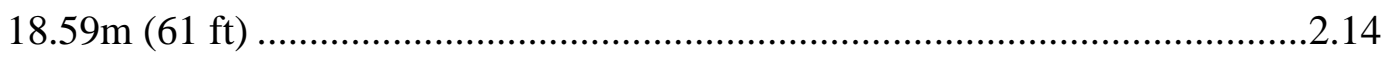

2.14 Test 29 - Hanford Nozzle with no flow straightener,

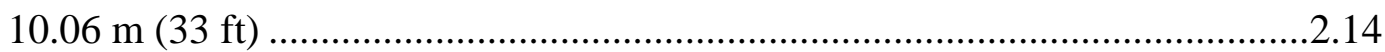

2.15 Test 30 - Elkhart Nozzle with no flow straightener .......................................14

3.1 Stream force on 54-cm (21-inch) diameter target ..............................................

3.2 Stream force on 27-cm (10.5-inch) diameter target .........................................

3.3 Jet force as percent of maximum theoretically possible distance

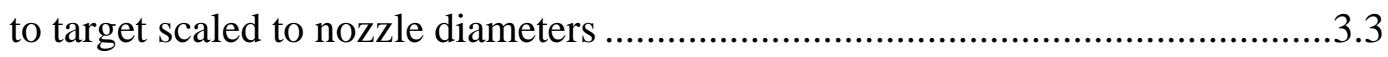

3.4 dP comparison for flow straighteners with nozzles and adapters ........................3.3

4.1 Proposed improved sluicing nozzle with integral removable flow straighteners and spanner dogs 


\subsection{Introduction}

\subsection{Background}

The baseline method for retrieval of nuclear materials processing wastes from the underground storage tanks on the U.S. Department of Energy sites is sluicing or "pastpractice sluicing" (Figure 1.1). This process utilizes one or more nozzles inserted through tank access risers

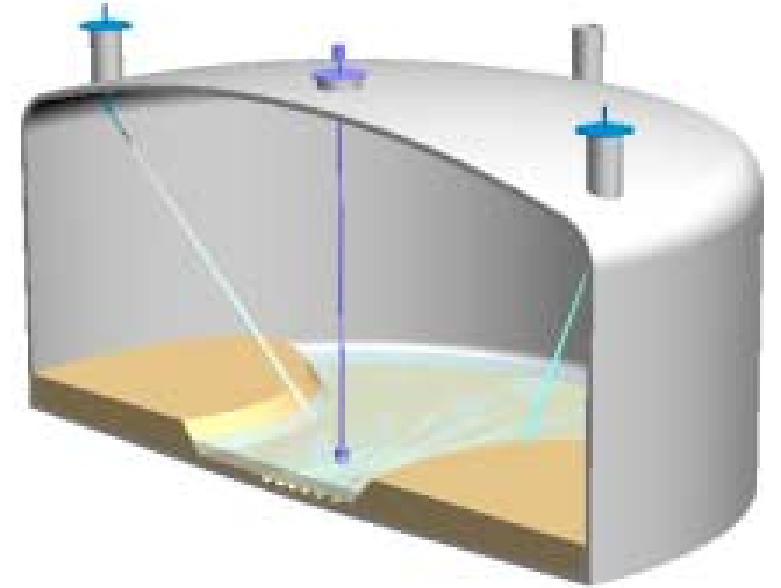
in the dome. The nozzles are mounted to a hanging sluicing monitor, which has essentially two degrees of freedom, tilt from the vertical and rotation about the vertical axis of the riser. The sluicing medium is typically recycled supernate from the tank farm, supplied to the nozzles at up to $1.03 \mathrm{Mpa}(150 \mathrm{psi})$ and $1.3 \mathrm{~m}^{3} / \mathrm{min}(350 \mathrm{gpm})$. The sluicing jet is directed

at the waste surface in a methodical pattern to dislodge and mix the waste into a pumpable slurry and carve drainage channels from the working area to the retrieval pump.
Figure 1.1 Sluicing concept - two sluicers are shown in opposing risers, and a single slurry pump is in the central riser. A single sluicer may be used with the slurry pump in the opposite side riser.

The slurry is pumped to the transfer

pipe loop using a submersible pump deployed through another access riser. The nozzles are typically $25 \mathrm{~mm}$

(1 inch) in diameter and of a Leach \& Walker style having a low angle tapered entry section and a straight throat about three diameters in length.

\subsection{Objective}

The purpose of these tests was to provide a simple comparison between four different sluice nozzle/flow straightener configurations and the nozzles with no flow straightener. The results were based on sluice stream contact force and continuity.

Sluice stream contact force was a quantitative measurement of the normal force generated by impingement of a sluicing jet on a target at various known distances. Stream continuity was assessed by comparison of force data from targets of two different diameters supplemented with visual data and subjective observation. The underlying assumption motivating this test is that a more coherent stream will provide more efficient and effective sluicing of tank wastes than will a stream that is relatively diffuse. While other testing experience and intuition may support this assumption, it is not the intent of these tests to do so. 
The results of this test are intended to identify enhancements to the sluicing method of tank waste retrieval.

\subsection{Scope of the Testing}

The scope of this test program is to determine the force generated by impingement of water jets on normal targets at various distances for each of the nozzle/flow straightener combinations being tested. Two target sizes were used to assess the stream coherence as a function of distance. Still photographs were also used as qualitative information on stream coherence at each distance. 


\subsection{Procedure}

\subsection{Apparatus}

\subsubsection{Nozzles}

Two nozzles were tested:

One nozzle was the standard Hanford nozzle, which is the baseline device currently in use at the Hanford site (Figure 2.1). It features a 2-1/2 inch ${ }^{1}$ Female National Pipe Thread (FNPT) connection and a 25-mm (1-inch) throat diameter. The test specimen used had a somewhat rough bore in the small end of the converging section. The Hanford nozzle is a decidedly robust piece of equipment at $5.1 \mathrm{~kg}(11.3 \mathrm{lb})$.
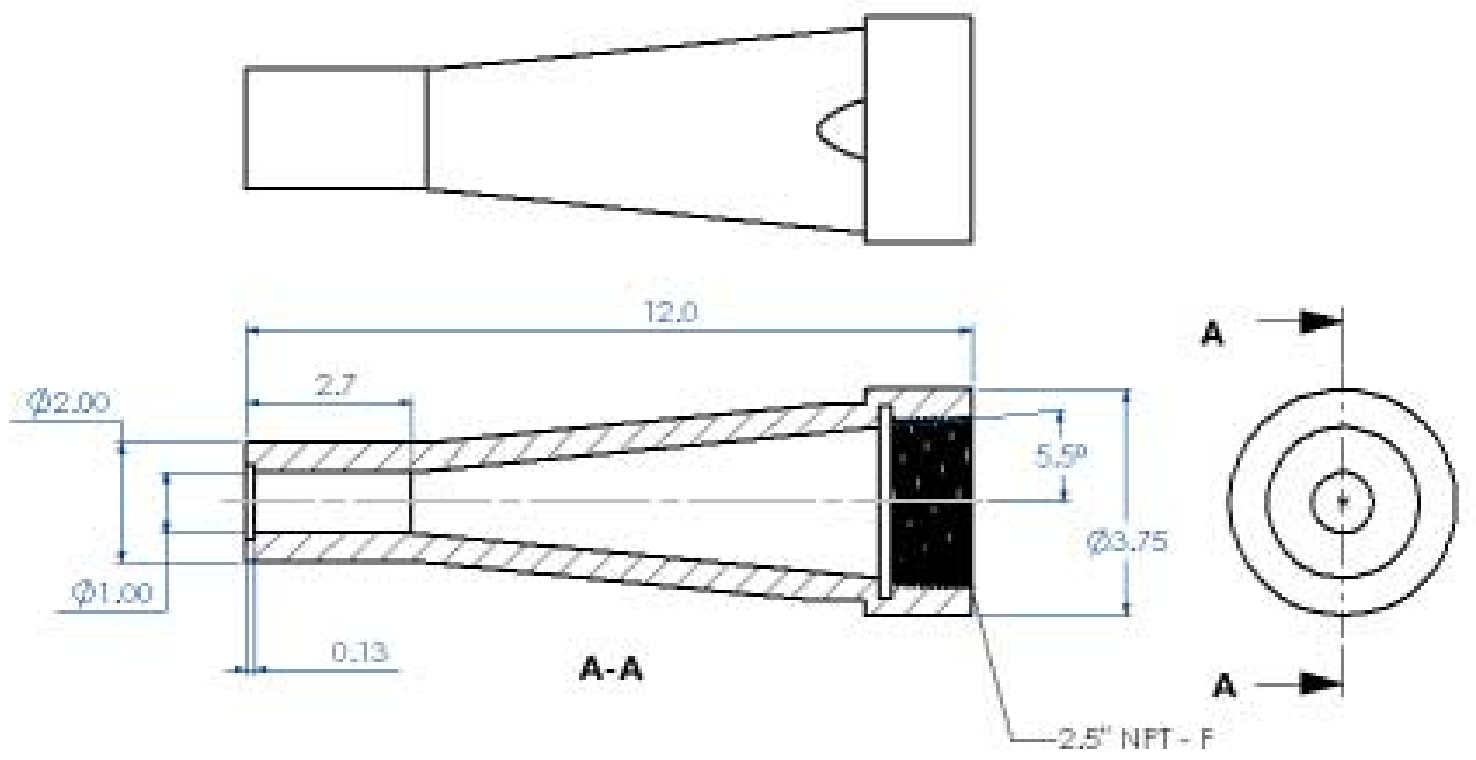

Figure 2.1 Hanford Nozzle (dimensions in inches).

The other nozzle used was an Elkhart Brass Mfg. Co. \#181 Brass Deluge Tip (Figure 2.2), which was specifically procured for comparison purposes. The \#181 nozzle includes a larger angle converging section and a smoother finish in the bore than the Hanford nozzle, and is much more compact and lighter weight. The brass material would be unsuitable for tank retrieval work; however, the geometry could easily be reproduced in a stainless steel. The \#181 nozzle features a 2-1/2 inch Female National Hose Thread (FNHT) inlet, which requires a gasket ring but provides a smooth internal wall through the connection.

\footnotetext{
${ }^{1}$ English units will be applied when they refer to a standard specification such as NPT pipe fittings, pipe side, etc., or where instruments actually read-out in specific English units or are specifically calibrated to an English unit. English units are also used within charts and figures.
} 
It was originally intended that a third nozzle would also be included in the testing. A Marconaflo sluicing nozzle was intended to be included in the tests; however, budget and schedule constraints prevented that from occurring. In lieu of actual testing, a manufacturer's test report and subsequent test data for the Marconaflo system has been appended for reference.

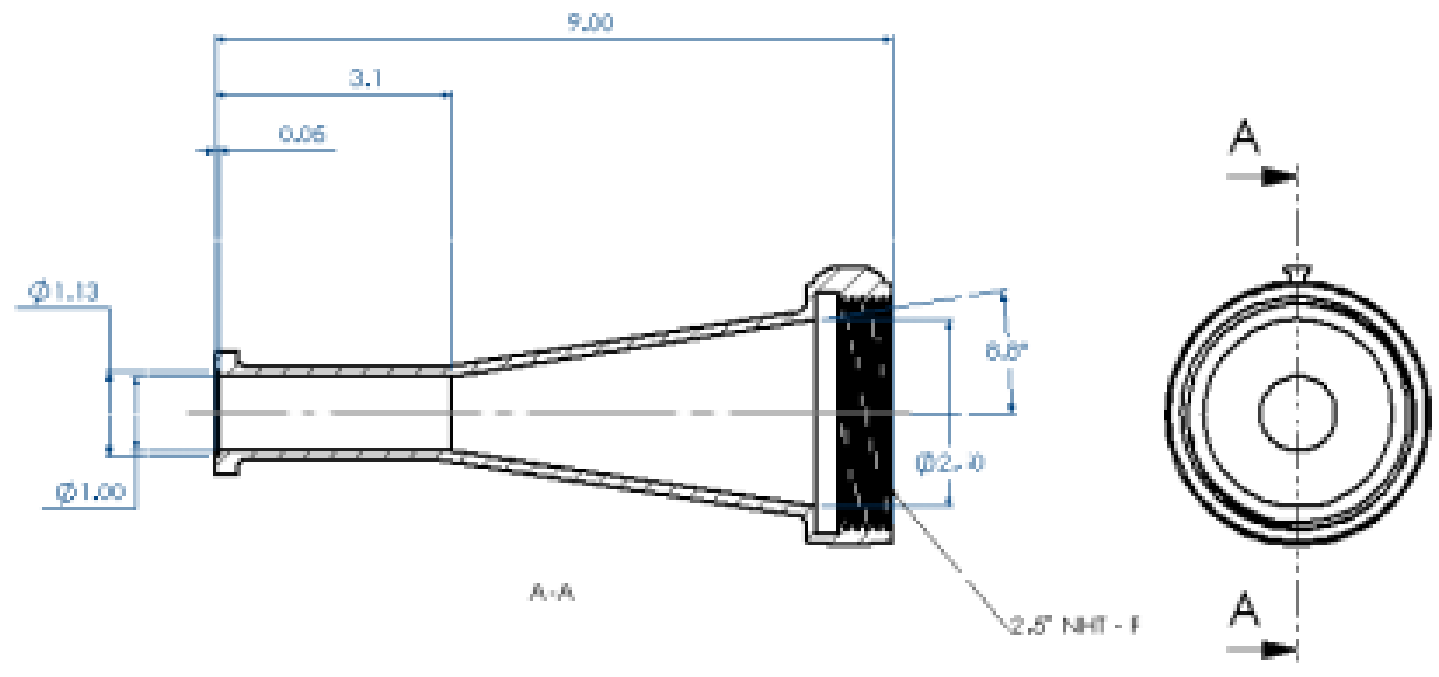

Figure 2.2 Elkhart \#181 Brass Deluge Tip.

\subsubsection{Flow Straighteners}

A flow straightener is designed to reduce or eliminate localized turbulence in flow streams flowing through cylindrical conduits. They typically accomplish this by inserting straightening vanes in the flow stream to prevent swirling of the flow stream as it progresses along the conduit. There are many types and designs of straightening devices in use in industry and these tests were limited in scope to include only two specific designs.

The first one was the standard Hanford flow straightener ( Figure 2.3), which is the baseline device. It is essentially a 0.6 meter ( $2 \mathrm{ft}$ ) length of 2-1/2 inch Schedule 40 steel pipe with Male National Pipe Thread (MNPT) ends that has four long straight vanes welded to the interior wall of the pipe and extending about $6 \mathrm{~mm}(1 / 4 \mathrm{inch})$ toward the center. The vanes are welded to the pipe with single welds of about $25 \mathrm{~mm}$ (1 inch) at each end and stand off the wall about $4 \mathrm{~mm}$ (5/32 inch) except at the welds. The remaining length of the vanes is completely unsupported. The device weighs $4.5 \mathrm{~kg}$ (10 lb). 


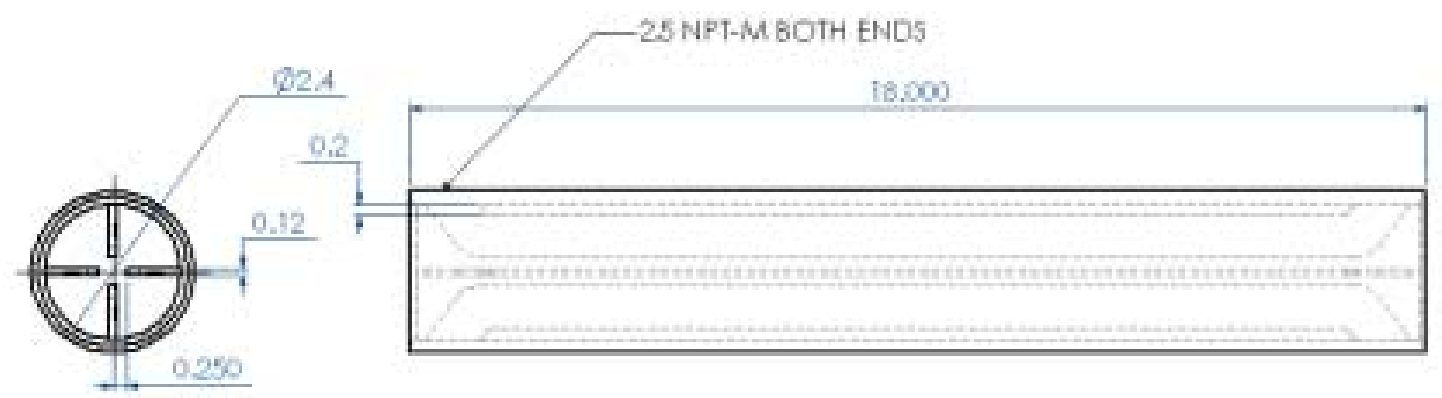

Figure 2.3 Hanford Flow Straightener.

The second device was an Elkhart \#282A Stream Shaper (Figure 2.4), which has an acetal plastic "honeycomb" piece mounted in a lightweight alloy housing with $2-1 / 2$ inch FNHT inlet and a 2-1/2 inch MNHT outlet. It weighs $0.7 \mathrm{~kg}(1.5 \mathrm{lbs}$.).

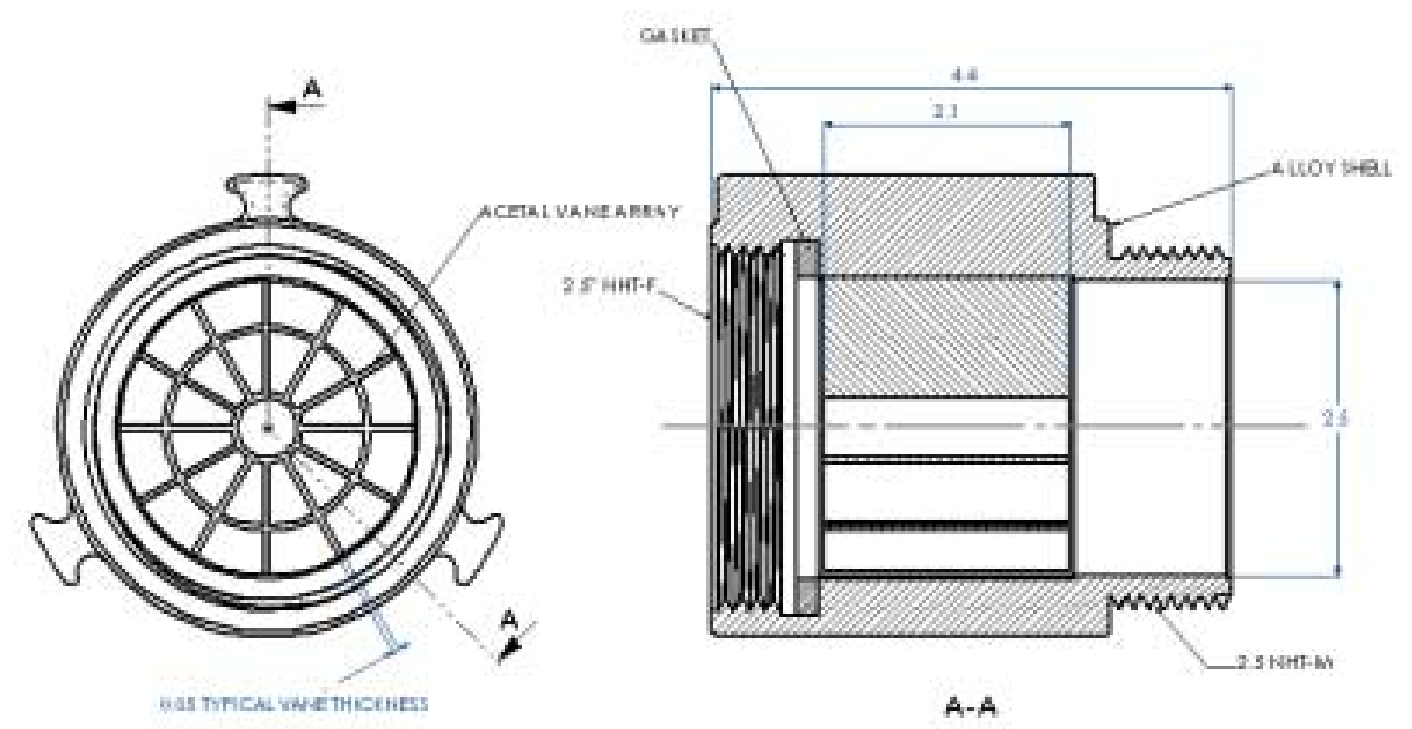

Figure 2.4 Elkhart Stream Shaper. 


\subsubsection{Combinations Tested}

The following combinations of flow straightener and nozzle were tested:

- Elkhart nozzle, no flow straightener,

- Hanford nozzle, no flow straightener,

- Elkhart nozzle, Elkhart Stream Shaper,

- Hanford nozzle, Hanford flow straightener, and

- Hanford nozzle, Elkhart Stream Shaper.

\subsubsection{Monitor}

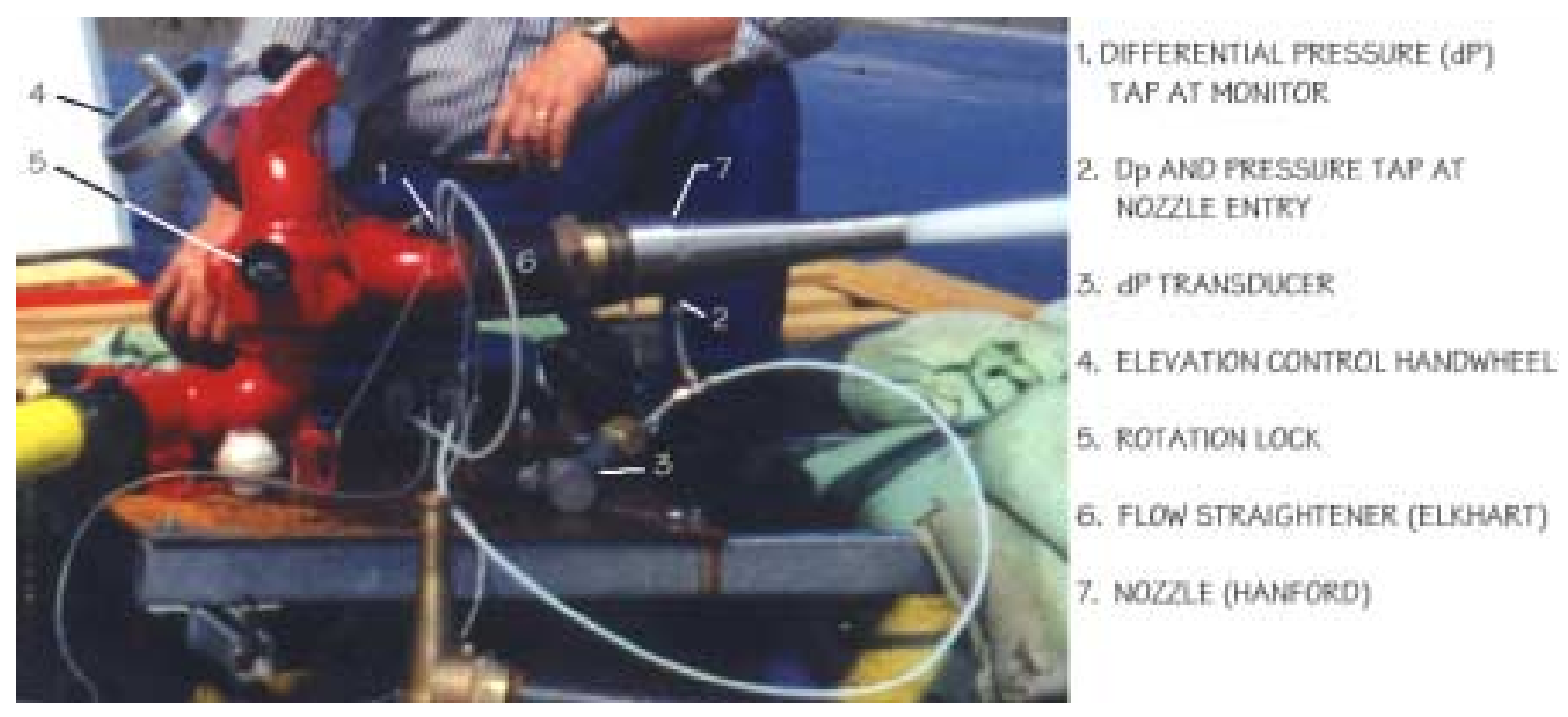

Figure 2.5 The monitor installation.

The nozzles and flow straighteners were mounted to a fire fighting deck-mount monitor (Elkhart Brass Mfg. Co. Model 8297-99 Stingray Deck Gun), which provided rotary and tilt motion (Figure 2.5). An operator controlled lateral rotation of the nozzle by pushing the nozzle back and forth while the vertical angle was adjusted using a hand-wheel. All the tests were performed with a nearly horizontal jet.

The monitor was bolted to a steel skid, which was secured in place by butting it against a fire hydrant bollard and staking the other end to the pavement. In addition, about $200 \mathrm{~kg}$ (441 lb) of sandbags were piled onto the staked end of the skid.

\subsubsection{Water Supply}

The water source was a municipal fire hydrant, which provided water at about $410-\mathrm{kPa}$ (60 psi) fed to a $9 \mathrm{~m}^{3}$ (2400 gallon) buffer tank through a totalizing flow meter and hose. 
The tank was vented and provided up to $1 \mathrm{~m}(3.3 \mathrm{ft})$ of suction head to the pump. The flow rate to the buffer tank was manually controlled using a simple gate valve.

A rented diesel pump (Power Prime model HH-125, 6 inch $\mathrm{x} 4$ inch) was in turn used to supply the water to the nozzles by means of two $8-\mathrm{m}(25-\mathrm{ft})$ lengths of $62-\mathrm{mm}$ (2.5-inch) fire hose in series with a coriolis flow meter (see Section 3.1.7 Instrumentation).

The pump proved inadequate to achieve the desired $1.03 \mathrm{MPa}(150 \mathrm{psi})$ at the nozzle due to inlet losses and pressure drop across the delivery hoses, monitor, and flow meter. As a result the tests were conducted at approximately $0.83 \mathrm{Mpa}(120 \mathrm{psi})$.

\subsubsection{Targets}

The targets were circular flat steel discs. One was $27 \mathrm{~cm}(10.5 \mathrm{inch})$ in diameter and the other one was $54 \mathrm{~cm}$ (21.0 inch) in diameter. The sizes were chosen to be the same as those used in the Marconaflo tests ${ }^{2}$ performed by the manufacturer. The targets were attached to a sensor that measured the force moments imparted to the target by the jet. The larger target was designed to easily attach over the top of the smaller target to reduce setup time (Figure 2.6).

The target mount had provisions for adjusting range, elevation, elevation angle, and bearing to the target. The target, item (3) in Figure 2.7, and force-moment sensor (1) were bolted to an existing bracket (2) and to a machinist's rotary cross-slide indexing table (7). The table was then mounted to a plate (6) mounted with threaded rod (16) and nuts (17) to provide pitch adjustment and to provide a method of clamping itself to a set of forklift forks. The forklift was driven to range location $+/-25 \mathrm{~mm}$ (1 inch) and roughly aligned by steering the forklift into position. Then the target alignment to the jet was fine-tuned with the indexing table. It was not known exactly how precisely the monitor could be aimed; therefore, some features of the target mounting were intended to support precise positioning and alignment of the target to the water jet. The forklift tilt mechanism proved to be controllable enough to present the target normal to the measured vertical jet angle within a few tenths of a degree, so the threaded rod pitch adjustment was not used. One bar of the target mount was extended to the side to provide a rough aiming target to minimize dwell time of the jet on the target, reducing risk of damage to the force-moment sensor. The monitor proved relatively easy to aim, so target alignment to the jet was easier than anticipated. The rotary table also proved very useful for quick bearing alignment.

\footnotetext{
${ }^{2}$ Letter Report: Marconaflo ${ }^{\mathrm{TM}} 1977$ Test Program, Interoffice Correspondence J.F. Ogg to W.N Sims. See Appendix
} 


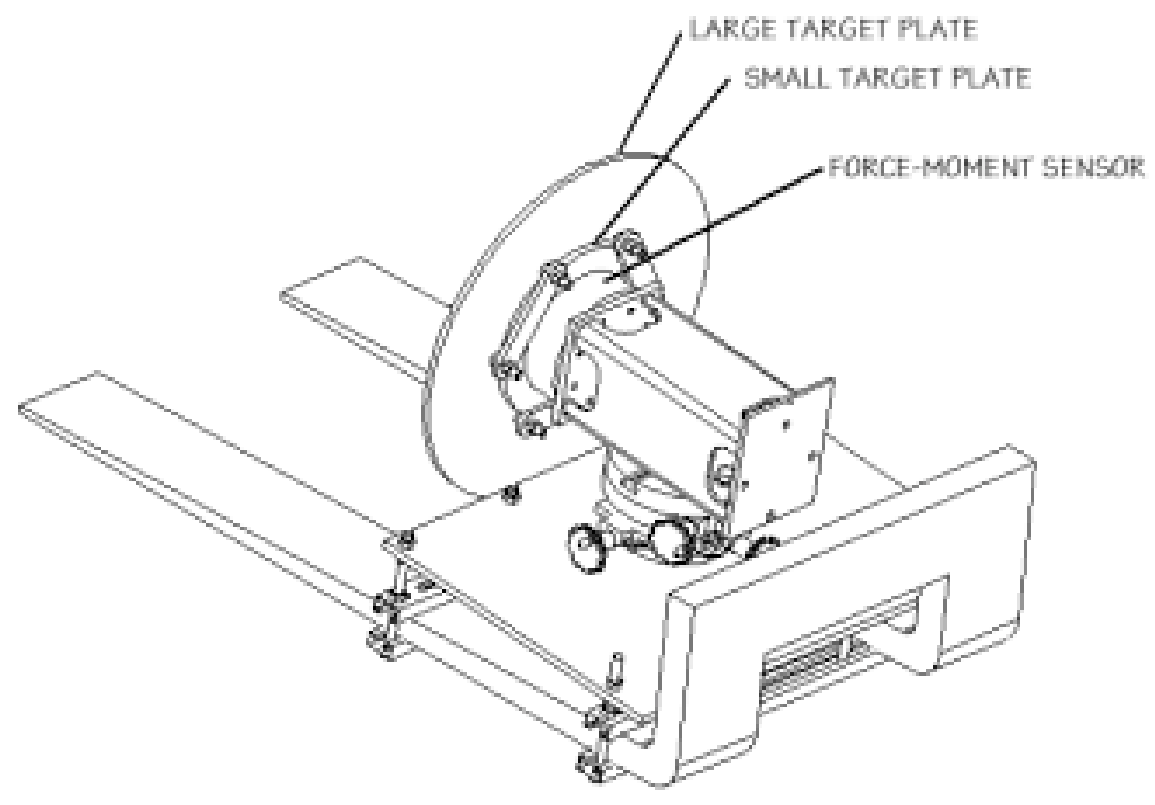

Figure 2.6 Rear view of target with 54-cm (21-inch) plate attached.

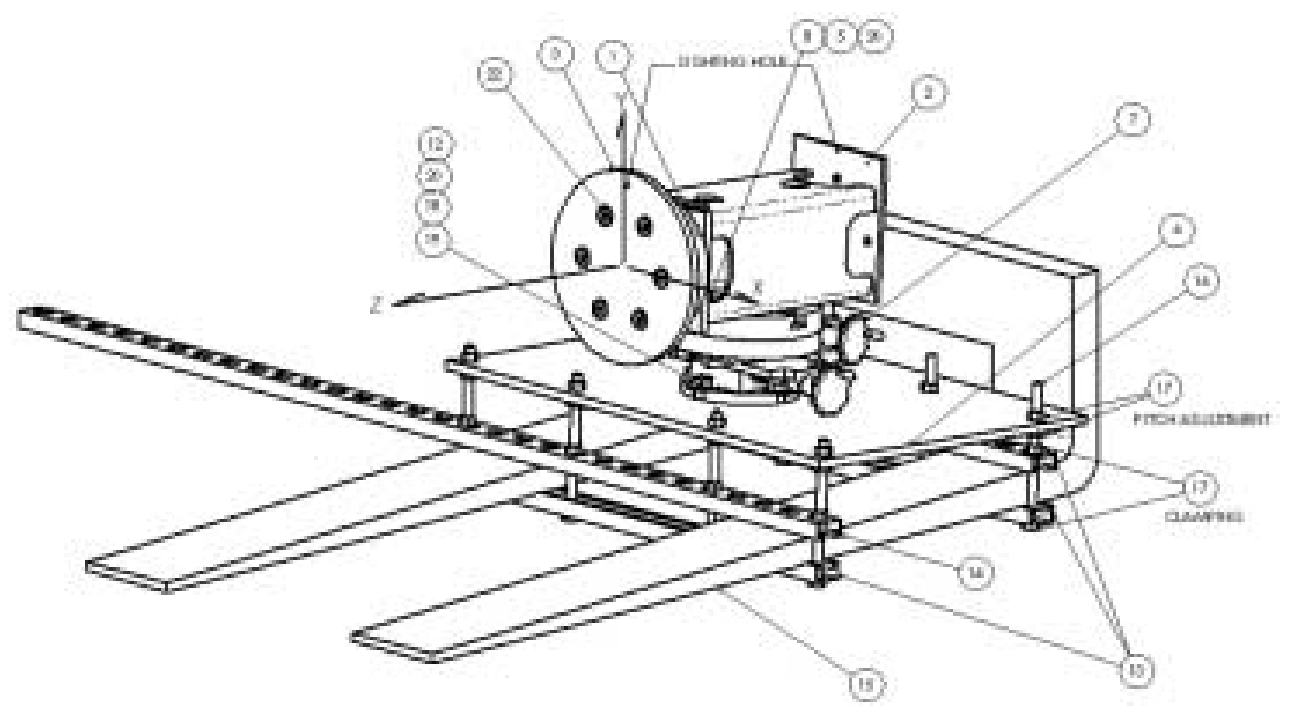

Figure 2.7 Front oblique view of target with $27-\mathrm{cm}$ (10.5-inch) plate only. Axes (X, Y, $\mathrm{Z})$ of the force-torque sensor reference frame are shown. 


\subsubsection{Instrumentation}

\subsubsection{Force Measurement}

The force and moment resulting from impingement of the sluice jet on the target plate was measured with an Assurance Technologies Inc. (now ATI Industrial Automation) flow temperature (F/T) Sensor Omega 600/7000, Serial Number (S/N) 3369. The device was calibrated by the vendor just prior to the testing. The Fx (force aligned with X-axis), $\mathrm{Tx}$ (Moment about the $\mathrm{X}$-axis), Ty and Tz axes exhibited non-linear error of slightly greater than $1 \%$. Fz force (axial force) output, the force of primary interest, was well within the $1 \%$ tolerance.

Output from the $\mathrm{F} / \mathrm{T}$ sensor is processed by a multiplexor (Mux) box and controller (same $\mathrm{S} / \mathrm{N}$ number) and supplied to the data acquisition system as a matrix of values updated at a user-controllable interval.

\subsubsection{Flow Measurement}

Water flow rate was measured with a Micro Motion Coriolis flow sensor Model DS3005155SU, S/N 162827 and transmitted to the data acquisition system by a transmitter Model RTF9739, S/N 1511597. The data acquisition system (DAS) was scaled so a 0-400 gpm flow (see Footnote 1 on page 2.1) corresponded to the 4-20 mA sensor output. The Micro Motion device also sensed water temperature, where the DAS was scaled from $10-40^{\circ} \mathrm{C}$ to correspond with a second $4-20 \mathrm{~mA}$ signal.

\subsubsection{Pressure}

Gage pressure at the entrance to the nozzles was measured with an Ametek pressure transducer, Model 88F005A20CSSM, S/N 40173-1-18, calibrated to 0-300 psi, with an accuracy of $+/-0.25 \%$. The unit was calibrated by AMETEK on January 4, 1995, with NIST trace number 45F-2-00290.

\subsubsection{Differential Pressure}

The differential pressure (dP) across the flow straightener was measured with a Rosemount differential pressure transducer/transmitter unit, model number 115 1DP4E22 B2, S/N 266332, with a range of $0-150$ inches water (see footnote on page 2.1) and an accuracy of $+/-0.1 \%$.

\subsubsection{Data Acquisition}

Signal outputs from the various sensors/transmitters were recorded using a portable computer with a real-time graphical data display, which facilitated rapid aiming and realtime data review. The software used was National Instruments Labview "Virtual Instrument" developed on a Labview system and downloaded to the portable as an executable program.

Analog data from the flow and pressure instruments was converted from the current signal to a voltage signal using precision $249 \Omega$ resistors and then to a digital signal with a National Instruments DAQcard-700S/N A14EE5.

Calibration factors for the pressure instruments were determined by linear regression of the calibration data. The sensing range of the initial $\mathrm{dP}$ instrument set up on the system 
proved to be insufficient for our test pressures. A second, un-calibrated, unit was brought out to the field and field calibrated over its normal sensing range and installed onto our test setup. The field calibration was performed using a static water column and showed the replacement instrument to have a nominal accuracy within $2 \%$ of full-scale.

The flow instrument was a MicroMotion D300 sensor coupled with an RFT Model 9739 transmitter. The reported range and accuracy for this system was 0 to $7000 \mathrm{lbs} /$ minute and $+/-0.2 \%$ of the rate, respectively.

\subsubsection{Geometry}

The distance between the nozzle and target was measured using a steel tape measure, where the accuracy of the measurement was estimated to be $+/-25 \mathrm{~mm}$ ( 1 inch) based on the measuring device and the rough method of measurement used. Test range point elevations were measured using a surveyor's transit and measuring rod. The manufacturer's stated accuracy for the transit was +/- 1/16 inch at $100 \mathrm{ft}$ distance (see Footnote 1 on page 2.1).

Jet exit and incident contact angles were measured with a hand-held digital inclinometer. Incident angle readings were made visually. The incident contact angles were measured by a student intern, who was positioned at an arbitrary distance away from the jet stream and who sighted the approximate stream angle along the top or bottom edge of the inclinometer and recorded the resultant angle reading. The device has a "hold" button to lock in the reading at any point and save it until manually cleared. This allowed the intern to sight the angle and press the hold button without trying to read the LCD readout while attempting to hold the device in position. The alignment of the inclinometer with the incident stream was necessarily subjective due to the diffuse stream and the visual alignment technique employed. As a result, the nominal $0.1^{\circ}$ accuracy of the device proved to be an insignificant magnitude.

The jet exit angle for the Hanford Nozzle was measured by placing the inclinometer on top of the straight exit section of the nozzle and reading the resultant angle. A visual technique was again used for the Elkhart nozzle because its exit nozzle shape was not straight.

Target plate angles were also measured using the inclinometer where one edge of the inclinometer was place against the target face and the forklift tilt was adjusted until the desired angle was achieved.

\subsection{Procedure}

\subsubsection{Setup}

The monitor and target were prepared as previously described and the range was laid out with target placement marks spray-painted on the pavement. The forklift with the mounted target assembly was positioned on the range at one of the target placement marks with a plywood spray shield and tarp installed to protect it.

The pump was set up near the buffer tank discharge and the instrumentation and hoses laid out to safely and efficiently feed the monitor and nozzle assembly. A pre-job discussion of the test procedures and applicable safety issues was held before attempting 
a few trial runs. The purpose of the trial runs was to shake down operations and instrumentation and to fine tune our test procedure. It was during the initial trial run that the first $\mathrm{dP}$ instrument was determined to have an inadequate range - $750 \mathrm{~mm}$ (30 inch) $\mathrm{H}_{2} \mathrm{O}$ to measure the $\mathrm{dP}$ across the Elkhart flow straightener. Before the next trial run the unit was replaced with the $3.75 \mathrm{~m}$ (150 inch) $\mathrm{H}_{2} \mathrm{O}$ unit, which was field calibrated immediately preceding its installation. The next trial run proved that the setup was ready to begin testing.

It was also discovered that water was able to penetrate along the small target mounting bolts and enter the sensor internal areas. This caused the sensor to malfunction. The unit was allowed to dry out, after which the sensor operated normally. The small target plate was reattached using silicone grease along the bolts and filling the space behind the plate with epoxy. As an added precaution the next trial runs used the larger target plate, which did not have any direct pathways for water to migrate to the sensor. The system checked out as fully functional after these modifications were completed.

\subsubsection{Testing}

\subsubsection{Target Alignment}

The initial test series were run with the large target plate as this reduced the risk of an early force/moment sensor failure from sensor contact with water. The target assembly was positioned at the desired distance mark on the ground and roughly aligned to the nozzle. A string line was pulled taught along the nozzle centerline and over the target and the target was rotated with the index table to align the target plate normal to the string. A pair of alignment marks on the target mount were used to sight against the string. A stream of water, at test pressure, was then shot at or just to the side of the target and the exit and incident angles measured. The water was shut off and the target vertical tilt was set normal to the incident jet $+/-0.5^{\circ}$ using the forklift tilt control and measuring the angle with the inclinometer.

A full series of tests using the small target were performed after all the large target tests were completed. The sensor operated normally throughout these tests as well, indicating that the modifications applied to the small target solved the water leakage problem seen during the trial runs. During the small target tests, the incident angle was not measured. The same target tilt angle used for the large target tests were used for the small target tests.

\subsubsection{Test Runs}

All tests were conducted with the pump operating at the governed engine maximum speed of $2200 \mathrm{rpm}$. Pressure measured at the nozzle was between $783 \mathrm{kPa}$ and $814 \mathrm{kPa}$ (115 and $118 \mathrm{psi}$ ) for all tests, and the measured flow rates were between $19.9 \mathrm{~L} / \mathrm{sec}$ and $20.3 \mathrm{~L} / \mathrm{sec}(315$ and $321 \mathrm{gpm})$. Water temperature varied between $19.4^{\circ} \mathrm{C}$ and $22.2^{\circ} \mathrm{C}$.

Initially, the jet was swept slowly across the target plate several times while incrementally changing the elevation for each pass. The data sample was taken starting with the jet off-target to get a baseline then the jet was slowly swept over the target. The intent was to post-process the data, selecting only force data corresponding to moments within a limited range of magnitude. This would select force data from a jet impinging 
on the center of the target. During the first several test runs, it was discovered that the jet could be aimed at the target accurately enough using the force and moment feedback rather than executing the sweeping action employed earlier. The jet was centered on the target and then held stationary for approximately 30 seconds. The result was that a larger sample of data was able to be collected with the jet centered and stationary than could be selected from data captured using the sweeping method. The remaining test runs were performed using this static-mode method.

Subsequent static-mode test runs were conducted by aiming the jet using instrument feedback, then moving the jet laterally off the target a couple of feet. With the jet offtarget, the data sample $(100 \mathrm{sec}$ at approximately $10 \mathrm{~Hz})$ was started. After a few seconds, the jet was redirected back at the target and brought to center, where it was held for approximately $30 \mathrm{sec}$. It was then slowly played back and forth a few times, taking it completely off the target at various intervals. This method captured a large number of data points with the jet on-target and, also, several distinct no-load force readings for detecting and compensating for drift in the force sensor (discussed in Section 3.3 Analysis).

\subsection{Data Analysis}

\subsubsection{Data Quality}

Pressure, temperature, and flow data were of secondary importance compared to stream coherence and impingement force. They were also mostly a function of the pump and water distribution system configuration than any test configurations. In all test runs, the pressure, temperature, and flow remained reasonably steady and consistent with no anomalies observed.

The force/moment sensor data was characterized by considerable variance, with $\sigma$ ranging from $5 \%$ of the mean for short-range tests to $>40 \%$ at the maximum range. The sensor also exhibited significant drift during several of the tests.

Initially, the force/moment sensor drift was ascribed to stress induced in the strain gage spider in the device resulting from imperfect mating of the mounting surfaces and bolt pattern. Imperfect surface mating is known to cause drift in this type of devices. To rectify the drift, the small target was re-mounted with epoxy putty between the mounting plate and the target plate. The screws were drawn finger tight until the epoxy set, then tightened an additional quarter-turn.

The large plate was installed over the small plate for the first series of tests to minimize risk of early sensor damage. Immediately after this process, the drift was reduced by $80 \%$ and within an hour, the drift had substantially disappeared. No significant drift was observed in the data taken with the large target plate bolted to the small plate.

When the large target plate was removed, drift in the Fz readings, manifest by the offset in $\mathrm{Fz}$ when the jet was directed away from the target plate at the end of a run, was observed. The drift appeared to be fairly linear over the $100 \mathrm{sec}$ of a run. The procedure of ordering a sensor bias reset (zeroing the force/torque readings) before starting the run was adopted. The revised procedure was to reset the sensor bias, then move the jet off target and start collecting data for approximately 10 seconds. Next, the jet was moved to 
center on the target and data was collected for approximately 30 seconds before beginning slow sweeps across the target or, in later tests, simply directing the jet off the target again. This resulted in clean (low-noise) Fz readings at each end of the data run, which could be used to estimate the sensor drift and compensate for it.

On one test (H25) a 100-sec data run was started and an unusually high drift was observed. This test run was aborted and the restarted after the first data set was saved. The repeat data set was appended to the first. Later, after testing was concluded and during analysis of the data, it was observed that the drift had reversed and vanished during the first abortive test and was not evident in the second test run (Figure 2.8). Unfortunately, this wasn't detected during the test period so most of the small-target data includes Fz drift as fast as $0.3 \mathrm{lbf} / \mathrm{sec}$. For low-drift-rates, a linear approximation is a reasonable compensation; however, it may undercorrect for higher rates of drift, where it appears that the rate of drift decays with time.

Sluicing Nozzle Test H25

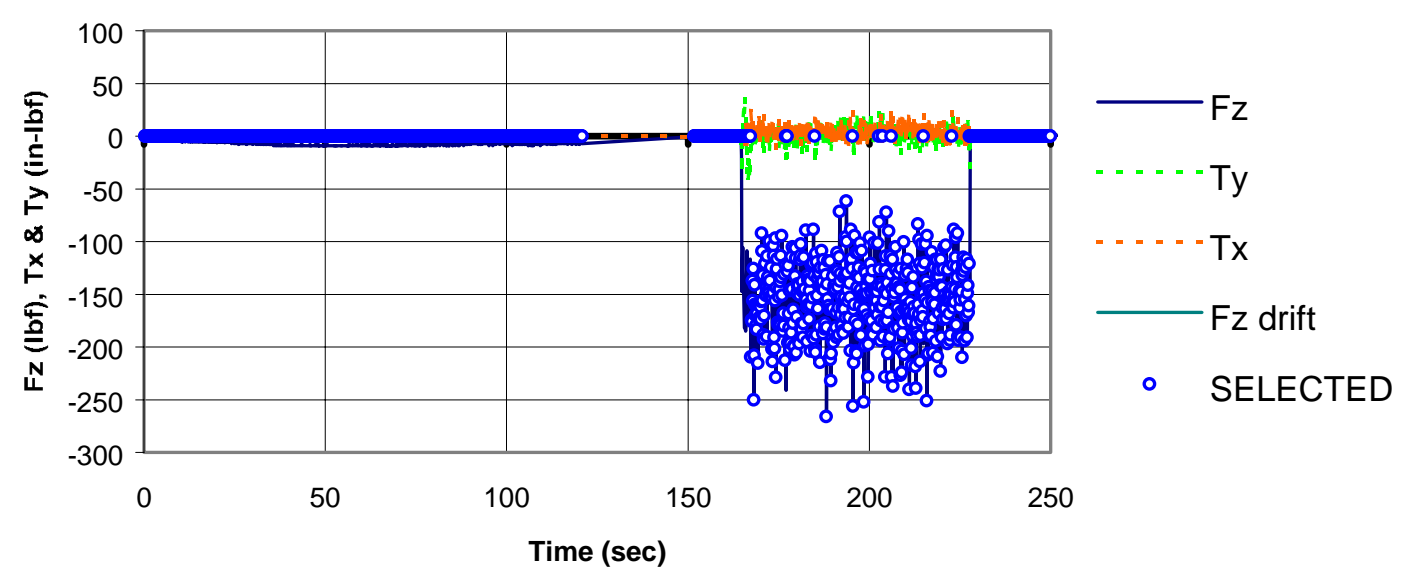

Figure 2.8 Data plot for Test H25 showing non-linear drift in Fz.

\subsection{Data Reduction}

The following selection and averaging techniques were used to arrive at the force values reported in Section 4, Conclusions.

\subsubsection{Data Filtering}

Fz (force component parallel to the Z-axis data (see Figure 2.7) was filtered using the following criterion:

a. The magnitude of $\mathrm{Fz}$ is greater than a threshold value, ensuring that the jet was impacting the target.

b. The magnitude of Tx and Ty (torque about the respective axes) at the same time was less than a threshold value, ensuring that the jet was near the center of the plate. 


\subsubsection{Data Selection}

The filtered data was selected by applying the criteria that any data point used had to be contiguous in the discrete time domain with four other data points passing the filter. The non-zero selected data were used to compute the average and standard deviation values reported.

\subsubsection{Selection Criteria}

The Fz criteria were determined by plotting the average Fz for both filtered and filtered/selected data as a function of the Fz limit. The limit was set at a value where the slope of the resulting curve was nearly zero. For a typical data set, some of the data was recorded when the jet was not centered on the plate, which resulted in the measured force being low and the moments either low or relatively high. A low Fz filter will include a lot of off-center data since the low force will result in a low moment as well, allowing the data to pass the Tx, Ty filter. This will reduce the average Fz magnitude markedly, as can be seen in Figure 2.9.

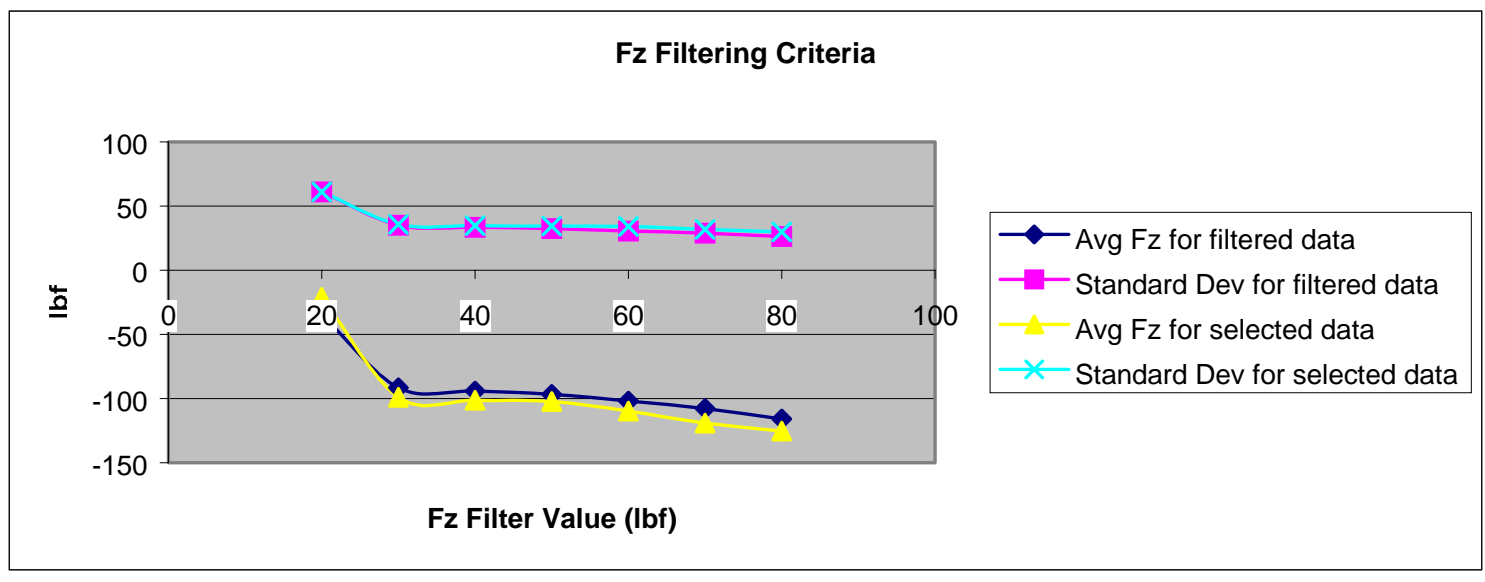

Figure 2.9 Typical filter value selection plot.

If the Fz filter value is set too high, it starts to bias the average by deleting data in the $-3 \sigma$ band. In cases where the force varied slowly through the filter value, the filter again introduced a bias in the same manner. In those cases, the data in the transitional periods were manually changed to a zero value to ensure that it would be filtered without biasing the selected data.

\subsubsection{Other Factors}

The most significant influence on the data quality was probably the wind. The tests were conducted outdoors in varying winds. The wind conditions for the 48-hour period in which the tests were performed are plotted in Figure 2.10. The time period of actual testing was about $0.3-0.6$ day and $1.3-1.6$ day. Most of the time the average wind velocity was less than $4.5 \mathrm{~m} / \mathrm{sec}(10 \mathrm{mph})$, and the direction was southerly (the range was aligned roughly south north, with the jet traveling north). During those conditions the 
wind had little effect on stream properties. After noon on the first day of testing the wind picked up to an average over $6.7 \mathrm{~m} / \mathrm{sec}(15 \mathrm{mph})$ and shifted to westerly, which had a much greater influence on the coherence of the stream. By about 2:30 P.M. that day, the direction was NW and the wind speeds had increased enough to suspend further testing that day. The tests that were run that day were for the Hanford nozzle, which was being tested at increasing range using both flow straighteners at each target distance. While the wind degraded the coherence of the respective streams, it did so randomly and without bias with regard to which flow straightener was being used. Essentially, the flow straighteners were tested against each other under reasonably similar conditions.

On the second day of testing, the wind was lighter and less steady in the morning. The test sequence was to change nozzle and flow straightener combinations at each given distance, so the combinations were tested under similar conditions at each target distance. The absolute performance data taken during the afternoons when the wind tended to pick up is somewhat suspect, but the comparisons between the various equipment combinations tested should remain valid

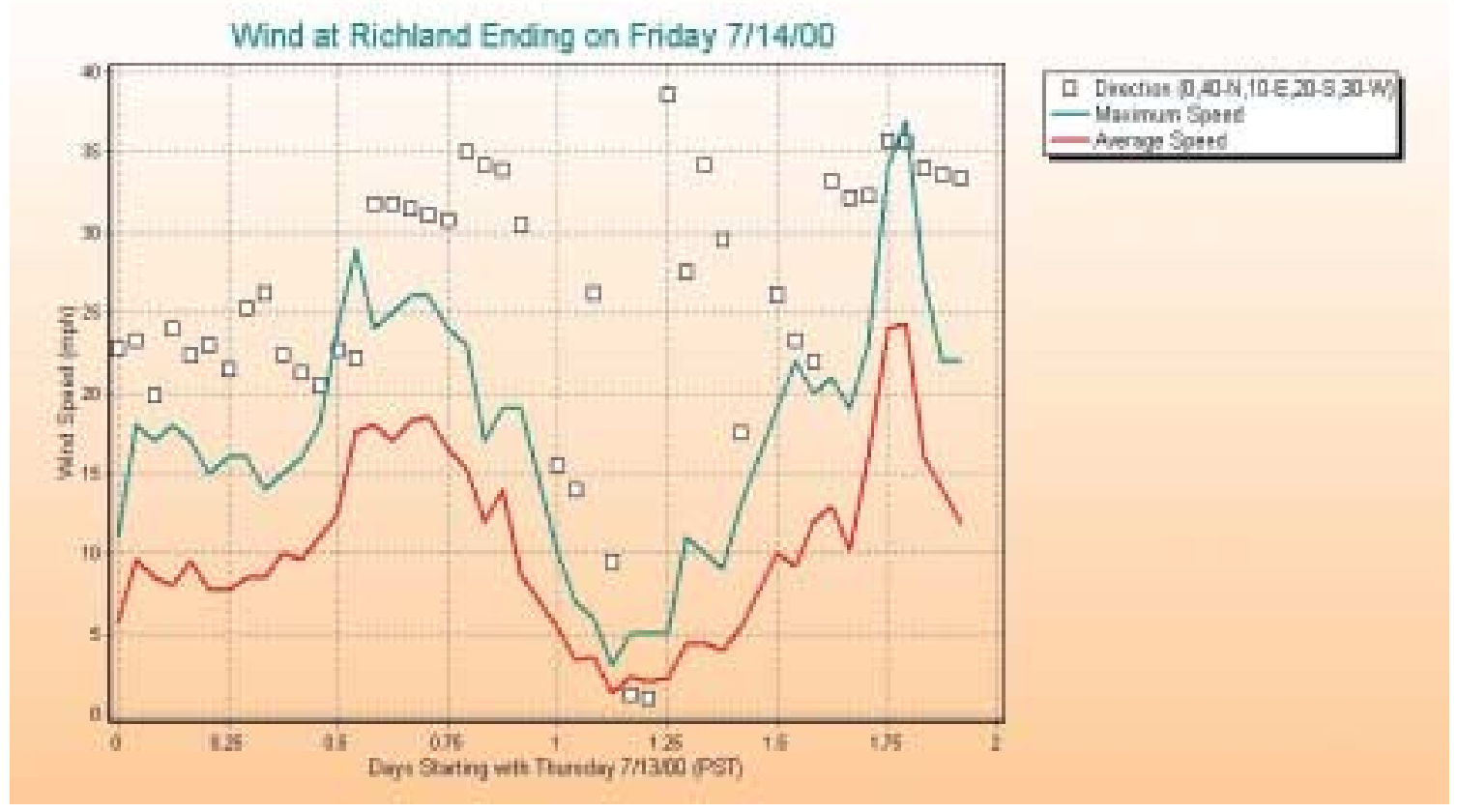

Figure 2.10 Plot of wind speed and direction during the testing. (Courtesy http://www.pnl.gov/waconia/Weather/Rosy_combo.ASP) 


\subsubsection{Empirical Observations}

Photographs were taken of the sluice streams to visually compare the stream coherence. Selected photos are presented in the following Figures 2.11 through 2.15.

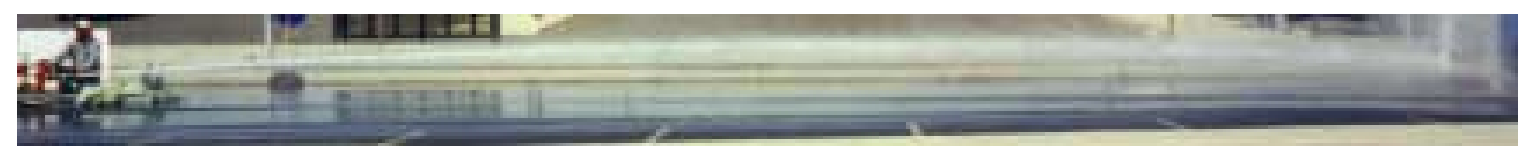

Figure 2.11 Test H17 - Elkhart nozzle with Elkhart Stream Shaper, $19.2 \mathrm{~m}(63 \mathrm{ft})$.

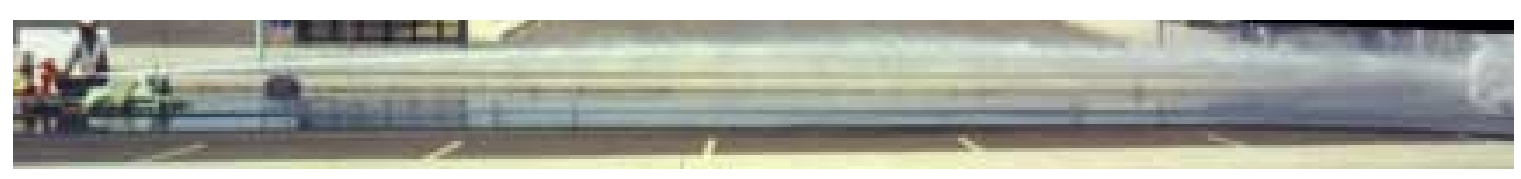

Figure 2.12 Test H18 - Hanford Standard nozzle with Elkhart Stream Shaper, $19.2 \mathrm{~m}(63 \mathrm{ft})$.

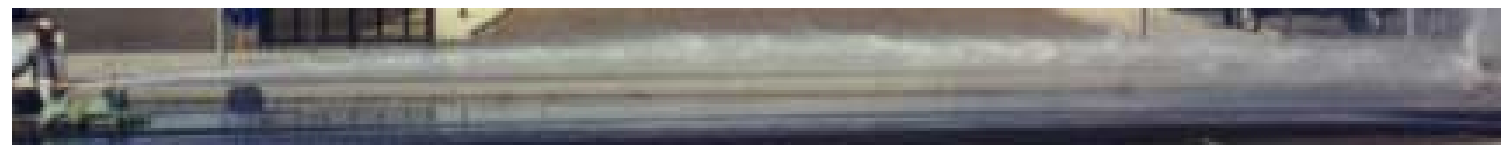

Figure 2.13 Test H19A - Hanford Nozzle with Hanford Flow Straightener, 18.59 m $61 \mathrm{ft})$.

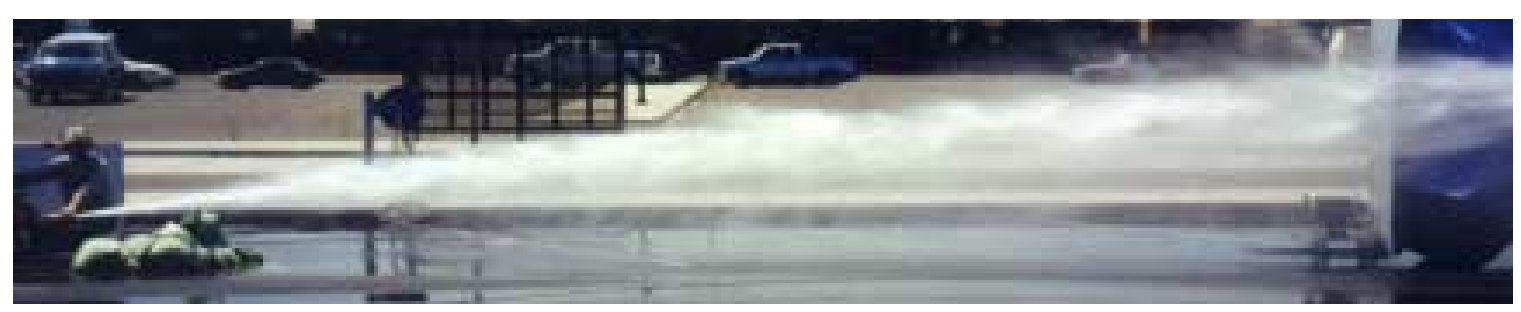

Figure 2.14 Test 29 - Hanford Nozzle with no flow straightener, 10.06 m (33 ft).

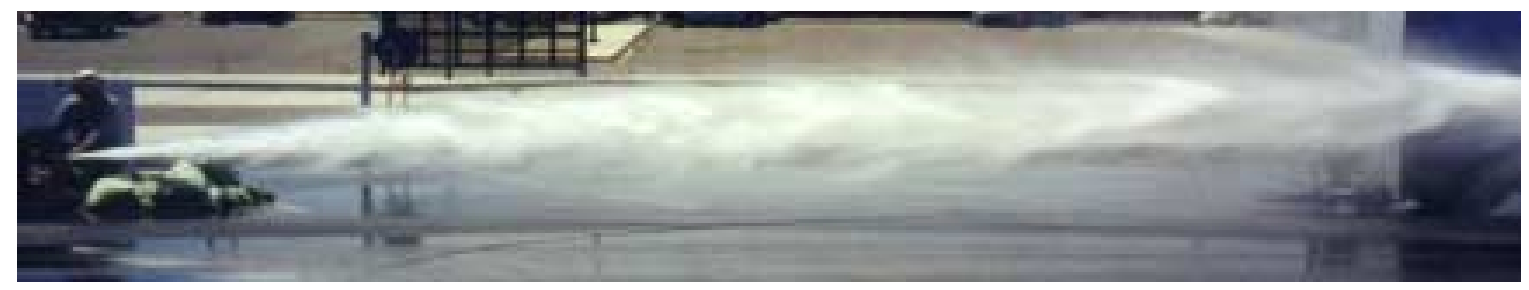

Figure 2.15 Test 30 - Elkhart Nozzle with no flow straightener. 


\subsection{Comparison to Theory}

The flow rates measured were found to correspond to a $\mathrm{Cd}$ value of .958 for both of the test nozzles. If all the momentum of a stream at the discharge rates observed were cancelled at the target, the theoretical reaction would be $791 \mathrm{~N}$ (178 lbf). Three of the averaged $\mathrm{Fz}$ data for short-range tests exceeded this value by no more than $2.9 \%$. This is considered insignificant compared to the variance of the data; one standard deviation for the most consistent data set was approximately $7 \%$ of the mean value. 


\subsection{Conclusions}

\subsection{Stream Coherence}

Two significant conclusions can be drawn from the numerical data:

1. The use of a flow straightener is absolutely necessary to maximize stream coherence and useful sluicing performance.

2. Tests using the larger target did demonstrate a clear distinction between the various nozzle/flow straightener combinations as evidenced by data plotted in Figure 3.1; however, Figure 3.2 shows that the Elkhart Stream Shaper provided measurably better stream coherence during testing with the smaller target plate. Note that the reaction force at close range for the small target tests agrees well (within 3\%) with the theoretical value maximum. The theoretical values are plotted in Figure 3.3. The data in all three figures was plotted after selection and filtering processes were complete.

\subsection{Pressure Loss - Flow Straighteners}

There is a significant difference in pressure drop in the nozzle when used without a flow straightener and when used with a flow straightener. However, the difference in pressure drop between the different combinations that used a flow straightener was insignificant. The pressure drop data for the various nozzle/flow straightener combinations are presented in Figure 3.1. Note that the ESS combination (Elkhart nozzle on Elkhart Stream Shaper) required no adapters while the HSS combination (Hanford nozzle on Elkhart Stream Shaper) required a 2-1/2 inch FNHT x 2-1/2 MNPT adapter between the flow straightener and the nozzle and the HSTD (Hanford nozzle on Hanford flow straightener) combination required a 2-1/2 inch FNHT x 2-1/2 inch FNPT adapter between the monitor and the flow straightener. The adapter fittings, which could be omitted from a sluicing monitor, add some degree of pressure drop to the applicable configurations. The differential pressure across the flow straighteners amounts to about $3 \%$ of the pressure at the nozzle and the difference between flow straighteners is only about $0.6 \%$ of the nozzle pressure.

\subsection{Limitations}

The following limitations regarding the comparison of streams produced by the nozzles without flow straighteners must also be identified. The raw data indicate that the Elkhart nozzle alone produces a more coherent jet than the Hanford nozzle; however, mounting the Hanford nozzle to the monitor required a FNHT x MNPT adapter. The adapter interface may have introduced a step in the wall at the pipe thread joint, exacerbating the turbulence. In addition, the jets from both nozzles, when used without flow straighteners, were very incoherent so accurate aiming was impossible, and it is by no means certain that the data is representative of the best possible performance of either nozzle. The slow and diffuse jets produced were certainly influenced more by the wind than were the tighter jets produced using the flow straighteners. The force/moment data plot was of no use for aiming the jets in these two tests, as the traces were so erratic that visual 
averaging was impossible. The data and photographs from the nozzle-only tests should only be used to support the first conclusion above.

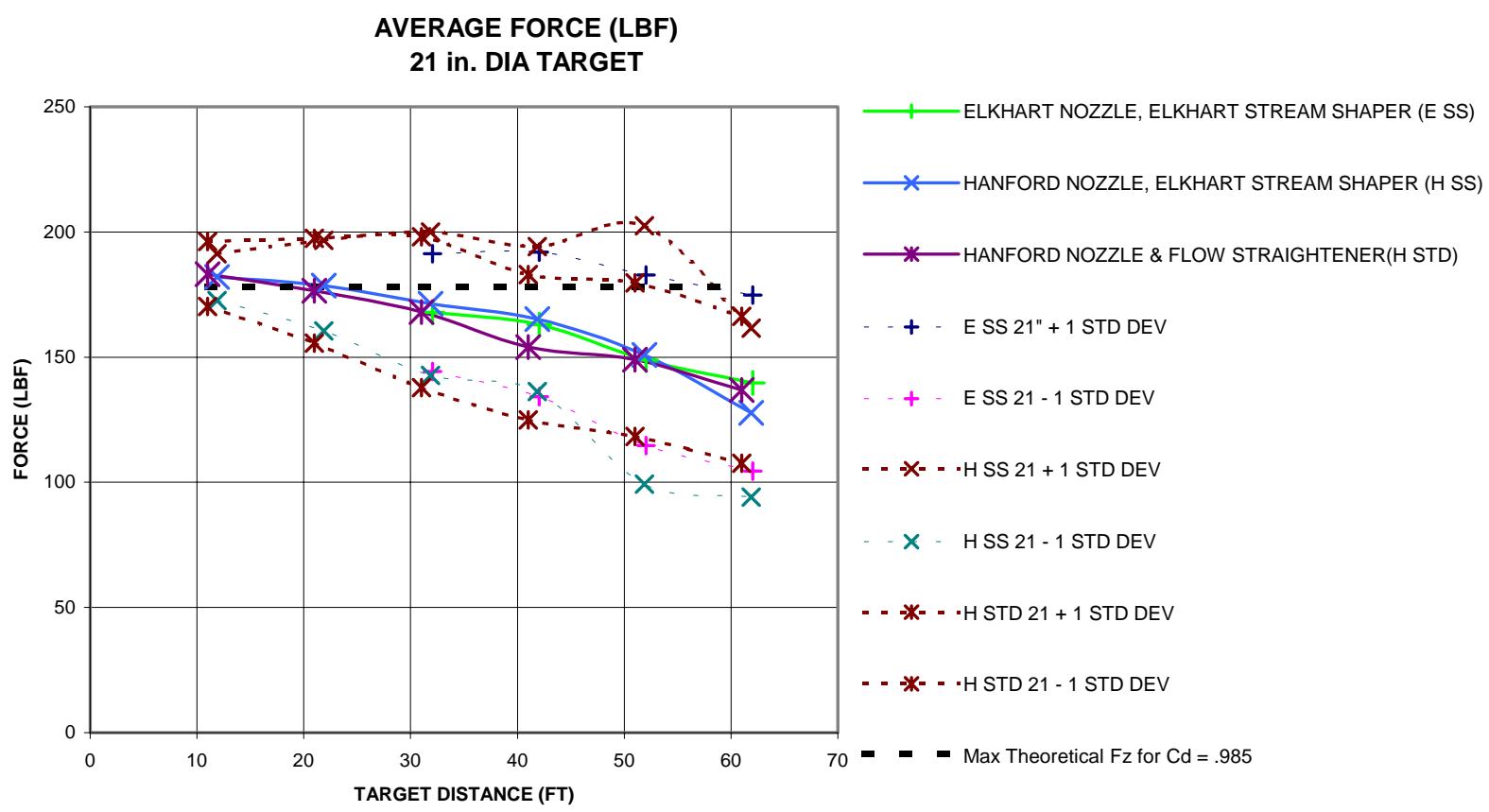

Figure 3.1 Stream force on 54-cm (21-inch) diameter target. The large variance of the data is indicated by the $1-\sigma$ bands plotted for each configuration.

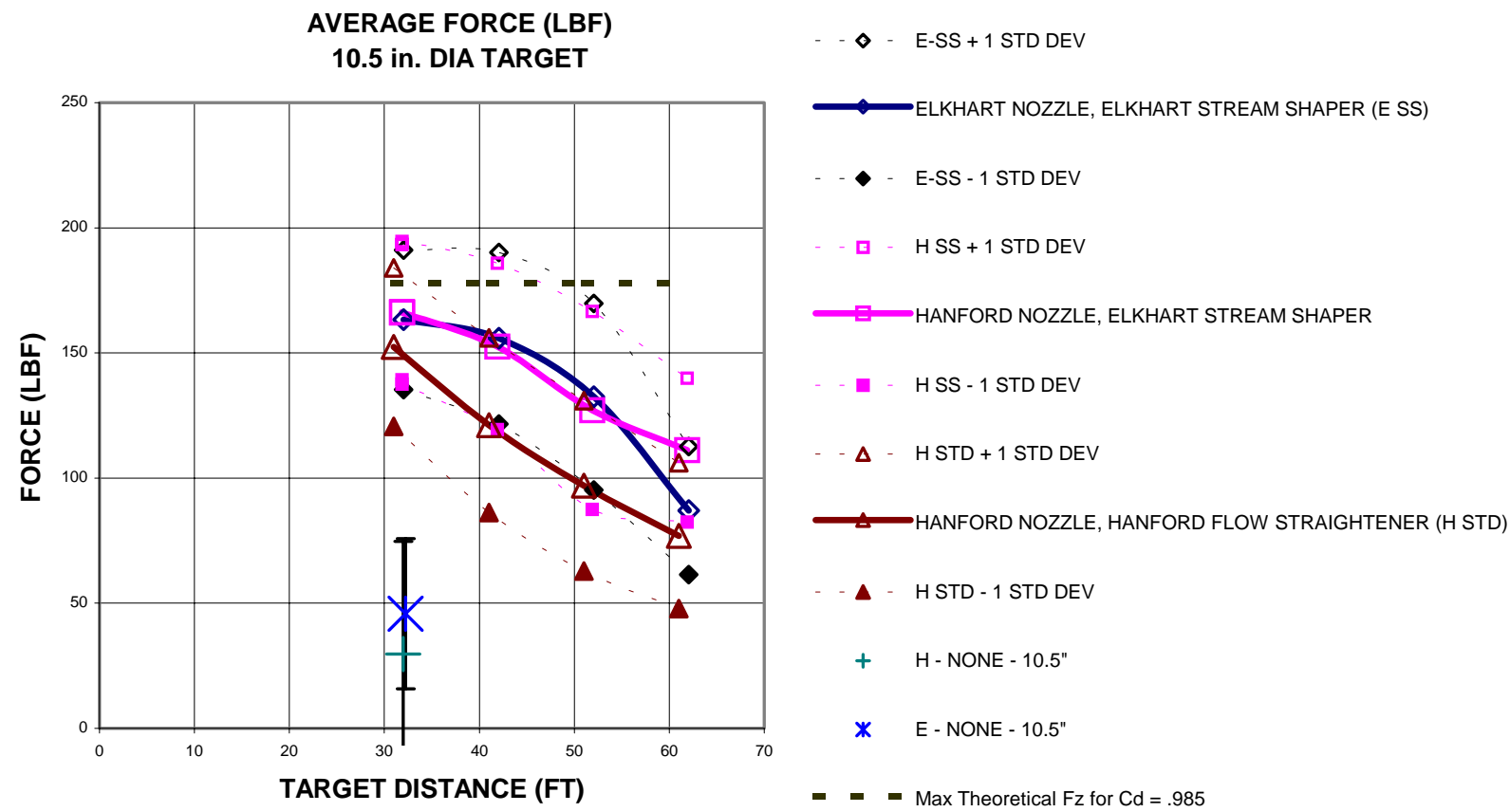

Figure 3.2 Stream force on 27-cm (10.5-inch) diameter target. H-NONE and E-None are shown with error bars of $1-\sigma$. 
FORCE AS \% OF THEORETICAL MAX

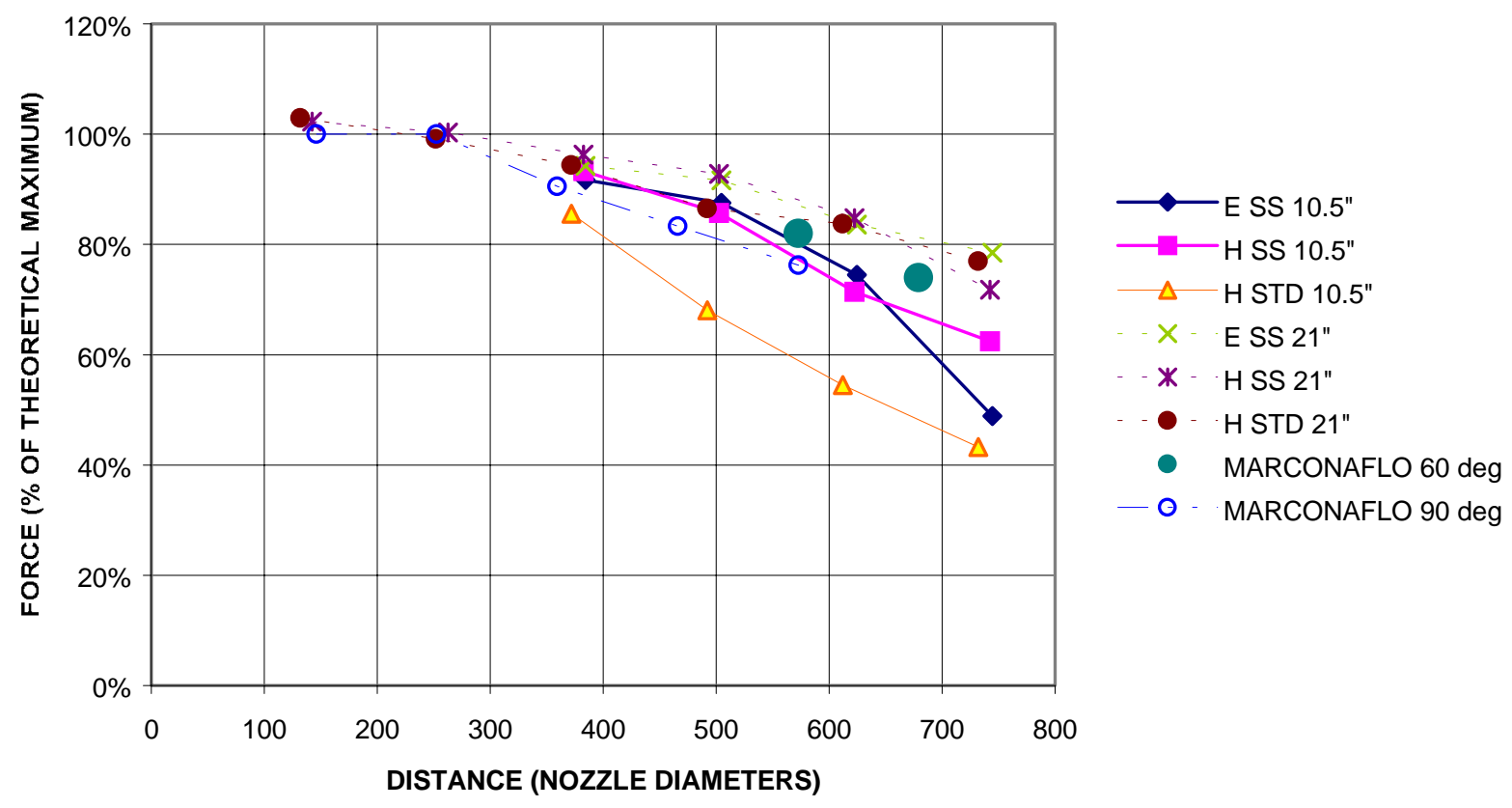

Figure 3.3 Jet force as percent of maximum theoretically possible, distance to target scaled to nozzle diameters. The Marconaflo data is for a $28.58-\mathrm{mm}$ (1.125-inch) nozzle at 360 psi on a 27-cm (10.5-inch) target (1).

dP for FLOW STRAIGHTENERS / NOZZLE ADAPTERS

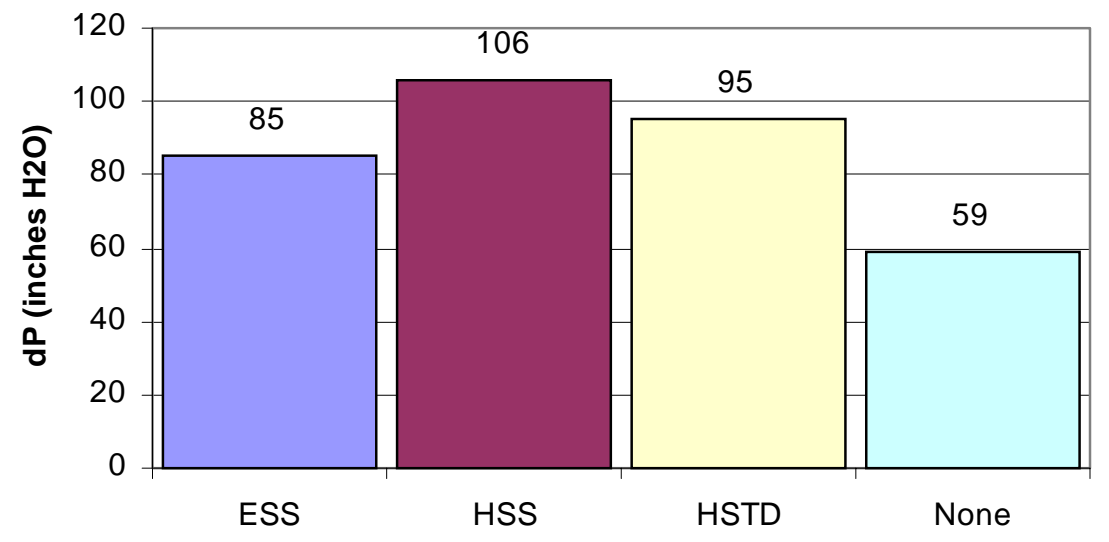

Figure 3.4 dP Comparison for flow straighteners with nozzles and adapters. 


\subsection{Recommendations}

The Hanford flow straightener should be replaced with a more effective design unless there are other compelling reasons to continue using it. One such reason might be that the Hanford design, having larger "cell" cross-section dimensions and a single passage, would be more tolerant of any large objects/solids in the sluicing liquid. The smaller "cells" of the Elkhart design could act as a strainer with larger particles and be prone to clogging unless the fluid is filtered upstream.

Also, the Hanford nozzle is unnecessarily heavy for the common pressures used for sluicing and could easily be reduced in mass without jeopardizing its longevity or performance. A cursory analysis indicated that at $2 \mathrm{Mpa}(300 \mathrm{psi})$ the current Hanford nozzle design has a safety factor of about 20 . It must also be considered that there may be no cost benefit to redesigning it solely to reduce the mass as long as it is not too heavy for normal handling and installation activities. Since the nozzle is machined from solid stock, it would typically require additional machine time to remove weight, which adds cost to the fabrication. Ultimately it would be more expensive to fabricate a lighter version of the current design.

If the nozzle were redesigned to also incorporate a smaller and more efficient flow straightener, similar to the Elkhart streamshaper (Figure 4.1), the cost benefit might be realized by improved performance. In addition, the incorporation could eliminate the extra bulk, torque, and mechanical connections associated with the existing nozzle/flow straightener design. Using National Hose Thread and fire apparatus wrench dogs would also allow a smooth bore through the connection to the monitor and use of simple hook spanners for installation instead of heavy pipe wrenches.

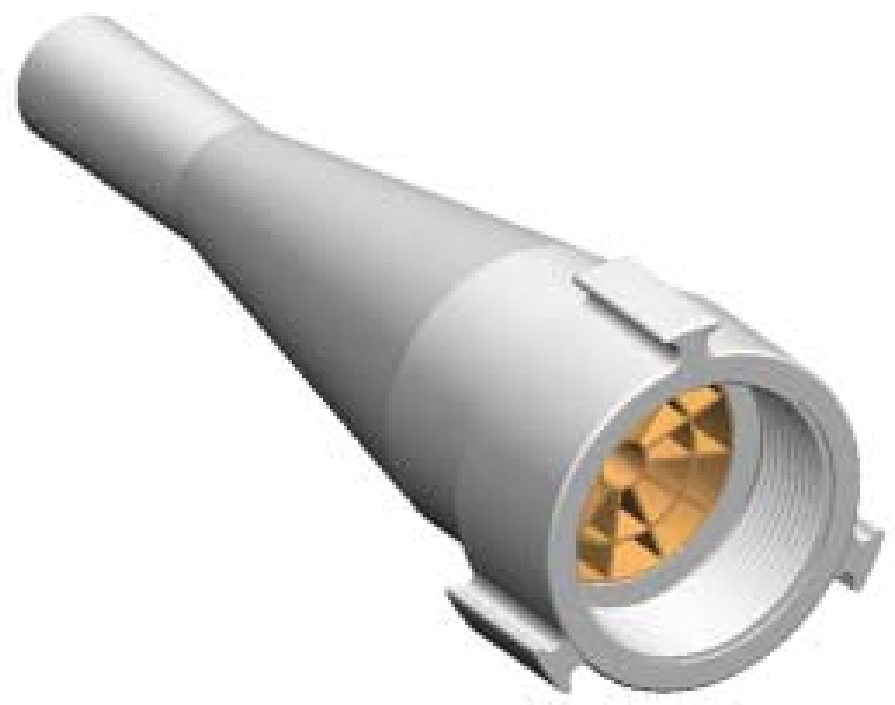

Figure 4.1 Proposed improved sluicing nozzle with integral removable flow straightener and spanner dogs. 
Careful attention should also be paid to the surface finish on the nozzle bore. It is unknown whether the manufacturing quality of this nozzle is representative of the nozzles used in the field, but the Hanford nozzle used in these tests had significant machine tool marks (several thousandths of an inch deep) in the narrow end of the converging section, which may have degraded its performance. For example, for the Reynolds number of about 9000 obtained at the test flow rate, the friction factor for $0.1 \mathrm{~mm}(.004$ inch) roughness in a $25-\mathrm{mm}$ (1-inch) bore will be .038 versus .032 for a smooth bore, an increase of $19 \%$ in shear at the wall. 


\section{Appendix}

\section{Marconaflo System}

The Marconaflo sluicing system uses a nozzle set at a fixed angle to the vertical supply pipe, which is rotated about its axis, so the jet sweeps a roughly conical pattern. The slurried waste then drains to the apex of the cone where it is retrieved by a slurry pump.

It appears from that data available that the Marconaflo system has a very effective nozzle and flow straightener, especially considering that the flow straightener is incorporated into the nozzle assembly. The Marconaflo nozzle assembly is comprised of an acutely angled and compact elbow, cast as a single piece, a flow straightener, and a short nozzle attached to the end. It is questionable whether the Marconaflo retrieval strategy is useful for complete cleaning of the large DOE tanks with relatively flat bottoms; however, it does appear to have merit and should be considered for any new storage facilities. 


\section{Distribution}

No. of

$\underline{\text { Copies }}$

\section{OFFSITE}

7 DOE/Office of Scientific \& Technical Information \& Information Release

1 D. W. Geiser, EM-50

US Department of Energy

Tanks Focus Area

Cloverleaf Building 19901 Germantown Road

Germantown, MD 20874-1290

2 Westinghouse Savannah River Co.

Bruce Martin and Eloy Saldivar 742-4G Building, Room 1

Aiken, SC 29801-802

\section{ONSITE}

1 DOE Tanks Focus Area Field Lead
T. P. Pietrok
K8-50

8 Tanks Focus Area Technical Team

B. J. Williams K9-69

2 Numatec Hanford Corp/Retrieval
P. W. Gibbons
K9-91

E. A. Pacquet

R3-73

2 Lockheed Martin Hanford Co.
C. Defigh-Price
T4-08
W. T. Thompson
R3-73

No. of

$\underline{\text { Copies }}$

14 Pacific Northwest National

Laboratory

K. M. Airhart K5-22

J. A. Bamberger K7-15

E. J. Berglin H3-26

J. L. Buelt K2-14

F. F. Erian K7-15

B. K. Hatchell (3) K5-22

D. R. Jackson (3) K5-22

O. D. Mullen (2) K5-22

M. W. Rinker K5-22 